\title{
Extensive sampling sheds light on species-level diversity in Palearctic Placobdella (Annelida: Clitellata: Glossiphoniiformes)
}

\author{
Sebastian Kvist $(\mathbb{D} \cdot$ Serge Utevsky • Federico Marrone $(\mathbb{D} \cdot$ Raja Ben Ahmed • \\ Łukasz Gajda • Clemens Grosser • Mair Huseynov • Uwe Jueg • \\ Andrii Khomenko - Alejandro Oceguera-Figueroa - Vladimir Pešić • \\ Mihails Pupins • Rachid Rouag • Naim Sağlam • Piotr Świątek • \\ Peter Trontelj $($ D $\cdot$ Luca Vecchioni (ib) Christian Müller
}

Received: 29 June 2021 / Revised: 21 October 2021/ Accepted: 8 December 2021

(C) The Author(s), under exclusive licence to Springer Nature Switzerland AG 2021

\begin{abstract}
The bloodfeeding leech genus Placobdella is dominated by North American diversity, with only a single nominal species known from Central America and one from the Palearctic region. This is likely due to considerable underestimation of Palearctic biodiversity, but investigations into potential hidden diversity are lacking. To shed light on this, the present study introduces new data for specimens initially identified as Placobdella costata from Ukraine (close to the type locality), Italy, Germany,
\end{abstract}

Handling editor: Christian Sturmbauer

Sebastian Kvist, Serge Utevsky and Federico Marrone have contributed equally to this work.

Supplementary Information The online version contains supplementary material available at https://doi.org/10.1007/ s10750-021-04786-5.

S. Kvist $(\square)$

Department of Natural History, Royal Ontario Museum,

Toronto, Canada

e-mail: skvist@rom.on.ca

S. Kvist

Department of Ecology and Evolutionary Biology,

University of Toronto, Toronto, Canada

S. Utevsky $(\varangle) \cdot$ A. Khomenko

Department of Zoology and Animal Ecology,

V. N. Karazin Kharkiv National University, Kharkiv,

Ukraine

e-mail: serge.utevsky@karazin.ua
Latvia, Montenegro, Bulgaria, Slovenia, Turkey, Azerbaijan, Tunisia, and Algeria, and uses both nuclear (Internal Transcribed Spacer [ITS] region) and mitochondrial (cytochrome $c$ oxidase subunit I [COI]) sequence data in phylogenetic and DNA barcoding frameworks, in order to better understand species-level diversity. Seven independent lineages are present in the trees, five of which show adequate separation at the COI locus to suggest their unique species-level status (COI distances between these clades range from 4.86 to $8.10 \%$ ). However, the ITS data suggest that speciation is recent or incipient in these clades, and that not enough time has passed for clear separation at this locus. We discuss the evolutionary and taxonomic implications of our findings and speculate on dispersal events that may have contributed to shaping this pattern of geographic distribution.

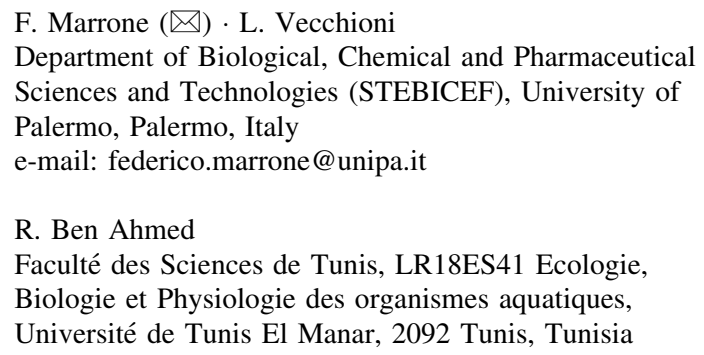

F. Marrone $(\bowtie) \cdot$ L. Vecchioni

Department of Biological, Chemical and Pharmaceutical Sciences and Technologies (STEBICEF), University of Palermo, Palermo, Italy

e-mail: federico.marrone@unipa.it

R. Ben Ahmed

Faculté des Sciences de Tunis, LR18ES41 Ecologie, Biologie et Physiologie des organismes aquatiques, Université de Tunis El Manar, 2092 Tunis, Tunisia 
Keywords Hirudinea Placobdella costata .

Cytochrome $c$ oxidase subunit I - Internal Transcribed Spacer $\cdot$ Genetic variation $\cdot$ Biodiversity

\section{Introduction}

The genus Placobdella (Annelida: Clitellata: Glossiphoniiformes) currently includes 24 nominal species and all but one of these are distributed across North and Central America (Siddall et al., 2005; Bielecki et al., 2012; Oceguera-Figueroa \& Pacheco-Chaves, 2012; Marrone et al., 2016; de Carle et al., 2017). The remaining species, Placobdella costata (Fr. Müller, 1846), is the type species for the genus and the only member with a Palearctic distribution (e.g., Siddall et al., 2005; Mabrouki et al., 2019); however, at least one record of human-mediated introduction of a North American Placobdella species into Europe exists (Soors et al., 2015). Members of Placobdella are recognized by their possession of two pairs of eyespots (the first pair coalesced), a single pair of caecate bacteriomes (bacteria-bearing organs) attached to the esophagus and bilobed ovaries (Siddall et al., 2005); these characters jointly serve as synapomorphies for members of the genus. Like most glossiphoniiform leeches, members of Placobdella display some degree

\section{Ł. Gajda · P. Świątek}

Institute of Biology, Biotechnology and Environmental Protection, Faculty of Natural Sciences, University of Silesia in Katowice, Katowice, Poland

C. Grosser

Elstertrebnitz, Germany

M. Huseynov

Institute of Zoology, National Academy of Azerbaijan, Baku, Azerbaijan

U. Jueg

Ludwigslust, Germany

A. Khomenko

Kharkiv Regional Center for Hydrometeorology, Kharkiv, Ukraine

A. Oceguera-Figueroa

Laboratorio de Helmintología, Departamento de Zoología, Instituto de Biología, Universidad Nacional Autónoma de

México, Mexico City, Mexico of parental care (they carry their offspring attached to the ventral surface) and are dorsoventrally flattened, often only slightly longer than wide, and can be found attached to the underside of rocks or submerged debris in freshwater settings, as well as attached to their hosts. All species of Placobdella are bloodfeeding and feed mainly on turtles, although some species will also readily feed on other amphibians and aquatic reptiles, as well as fish, birds, and mammals (including humans) (Jones \& Woo, 1990; Siddall \& Gaffney, 2004; Siddall \& Bowerman, 2006; Vamberger \& Trontelj, 2007; Moser et al., 2010; Oceguera-Figueroa et al., 2010; Schulz et al., 2011; Cichocka et al., 2021). Their feeding mode and overall high abundance in most freshwater bodies is suggestive of their high impact on ecosystems. This is further evident by virtue of members being known to vector blood-borne parasites, such as hemogregarines and trypanosomes, to their hosts but incidence and effects on fitness remain unknown (Siddall \& Desser, 1990; 1991, 2001; Arizza et al., 2016; Scardino et al., 2022).

Until recently, the phylogenetic relationships within Placobdella were largely unexplored, mainly due to the lack of comprehensive analyses covering a broad swath of the diversity. Beyond constraining our general knowledge of the evolutionary histories of the species, the lack of a robust phylogenetic hypothesis

\section{Pešić}

Department of Biology, University of Montenegro, Podgorica, Montenegro

M. Pupins

Department of Ecology, Institute of Life Sciences and Technologies, Daugavpils University, Daugavpils 5400, Latvia

R. Rouag

Université Chadli Bendjedid, El Tarf, Algeria

N. Sağlam

Department of Aquaculture and Fish Diseases, Firat University, Elazig, Turkey

P. Trontelj

Department of Biology, Biotechnical Faculty, University of Ljubljana, Ljubljana, Slovenia

C. Müller

Animal Physiology and Biochemistry, Zoological Institute and Museum, University of Greifswald,

17489 Greifswald, Germany 
has also haltered our understanding of the dispersal events between continents. In an attempt at remedying this, de Carle et al. (2017) reconstructed the phylogenetic relationships between the known members of the genus. The study revealed a large amount of undescribed North American diversity and also evinced a North American origin for the genus with a relatively late, single dispersal event to the Palearctic (de Carle et al., 2017). This might, in part, explain the overall paucity of Palearctic species diversity, a phenomenon that is mimicked in other glossiphoniiform taxa, such as members of the genera Theromyzon and Helobdella (Oosthuizen \& Davies, 1993; Sağlam et al., 2018; Iwama et al., 2019); both of these genera include only few European representatives and are otherwise outweighed by North American diversity. It is still likely, however, that Palearctic diversity within Placobdella is grossly underestimated, and that historical and contemporary investigations have applied the name $P$. costata to any Palearctic specimen without assessing levels of morphological, genetic, and behavioral variation that might be indicative of separation between species.

The limits of the geographical distribution of $P$. costata also remain unknown, and the native status of the species in some regions has recently been questioned (e.g., Vecchioni et al. 2021). Regardless, the species has been recorded from across Scandinavia, the Baltic region, the British Isles, along the European Mediterranean coast and in most central European countries (Bielecki et al., 2012 and references therein). Indeed, records of the species also expand into several North African countries, including Morocco, Algeria, and Tunisia as well as Palestine, Syria, Iran, and the northern Caucasus and Transcaucasia in Central Asia (Pawłowski, 1936, 1968; Bielecki et al., 2012; Ben Ahmed et al., 2015; Bashirichelkasari \& Yadollhvandmiandoab, 2017; Laghzaoui \& Abbad, 2020; Solgi et al., 2021). The type locality for the species lies on the Crimean Peninsula (see Ben Ahmed et al., 2015), a region of recent unrest, which exacerbates any attempt at gathering fresh material. In order to assess the species-level diversity of Palearctic Placobdella, we herein produce new sequence data for material recently collected in Ukraine (including the Kherson Region of southern Ukraine, in proximity to the type locality), Italy, Germany, Latvia, Montenegro, Bulgaria, Slovenia, Turkey, Azerbaijan, Tunisia, and Algeria, and combine these data with previously published information in both phylogenetic and genetic variation analyses.

\section{Material and methods}

Specimen collection

Between 2015 and 2019, several specimens of Placobdella costata were collected from Ukraine, Italy, Germany, Latvia, Montenegro, Bulgaria, Slovenia, Turkey, Azerbaijan, Tunisia, and Algeria (see Fig. 1 and Table 1). All specimens were initially identified using specialized literature (e.g., Mann \& Watson, 1954; Sawyer, 1986; Sağlam, 2001) and the identities were later corroborated by DNA barcoding using the COI locus. Specimens were variably collected from their host, or from rocks and debris. The leeches were either relaxed by the addition of a small amount of ethanol to pond water and thereafter fixed in $95 \%$ ethanol, or fixed directly in $95 \%$ ethanol. Voucher specimens are lodged in both private and public repositories, and are available from the first authors upon request.

DNA extraction, amplification, and sequencing

To avoid contamination by bloodmeals inside of the leeches, a small piece of tissue was cut from the caudal sucker of each specimen. DNA extraction was accomplished via a DNeasy Tissue Kit (Qiagen, Valencia, CA, USA), an InnuPrep DNA Mini Kit (Analytik Jena, Jena, Germany), or a BIORON tissue kit (BIORON, Römerberg, Germany) following the manufacturers' protocols. Thereafter, partial sequences for the mitochondrial cytochrome $c$ oxidase subunit I (COI) gene was amplified using the universal primers LCO1490 and HCO2198 (Folmer et al., 1994), and portions of the nuclear internal transcribed spacer (ITS) were amplified using a combination of the primers ITS3, ITS4 and ITS5 (White et al., 1990). Polymerase chain reactions (PCRs) were carried out in $25 \mu \mathrm{l}$ reactions consisting of $16.39 \mu \mathrm{ddH}_{2} 0 ; 2.5 \mu \mathrm{l}$ buffer; $2.5 \mu \mathrm{MgCl}_{2} ; 1 \mu \mathrm{l}$ of each primer; $0.56 \mu \mathrm{l}$ dNTPs at $10 \mathrm{mM}$ concentration; $0.05 \mu \mathrm{l}$ Platinum Taq polymerase (Invitrogen, Carlsbad, CA); and $1 \mu$ total genomic DNA. PCR amplification used the following protocols for COI: $94^{\circ} \mathrm{C}(5 \mathrm{~min}$ ) followed by 30 cycles of $94^{\circ} \mathrm{C}(45 \mathrm{~s}), 40^{\circ} \mathrm{C}(45 \mathrm{~s}), 72^{\circ} \mathrm{C}(45 \mathrm{~s})$, and final 


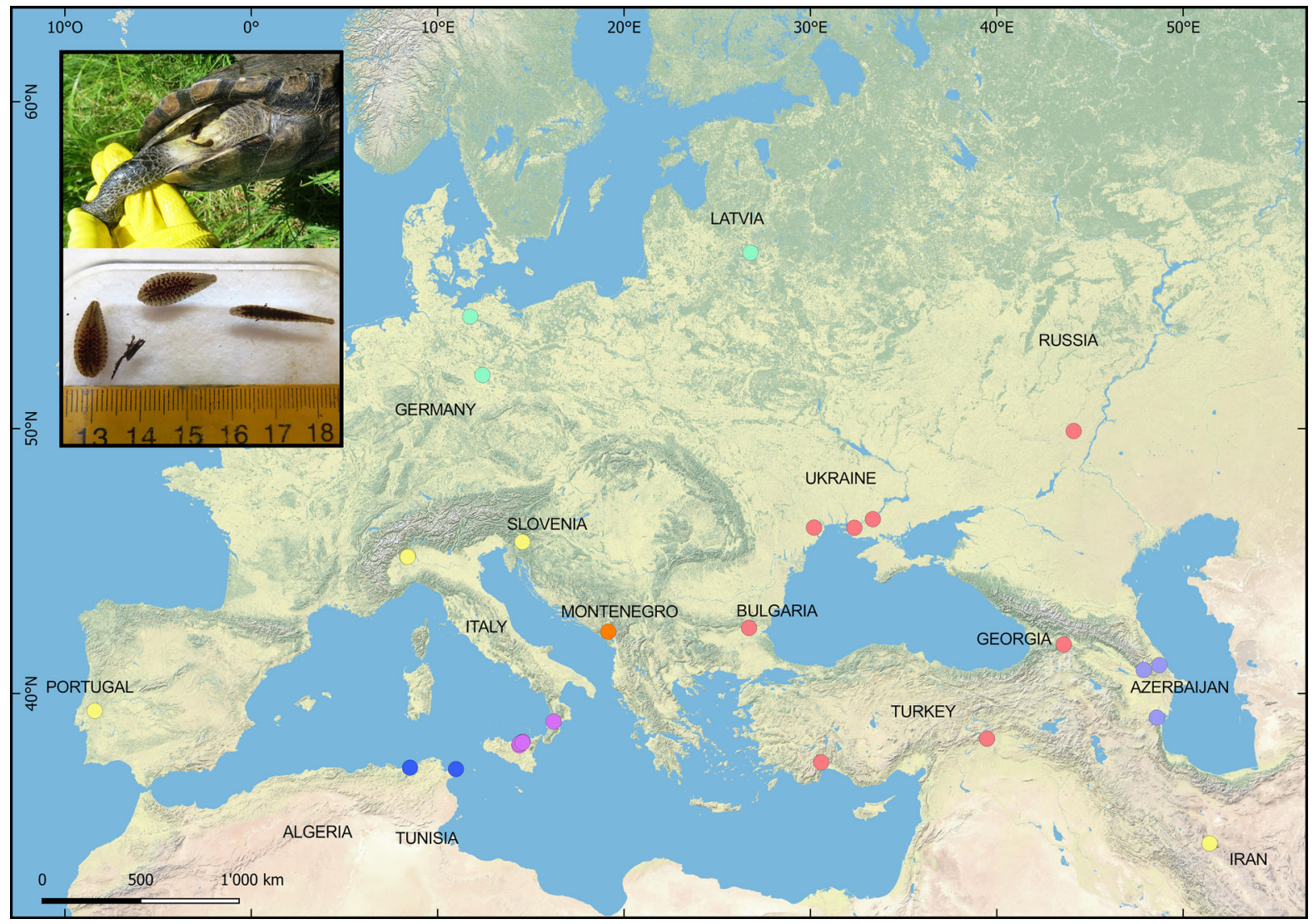

Fig. 1 Map showing the sampling sites for the included specimens of Placobdella costata. Note that the sites for the Iranian, Portuguese, Russian, and Georgian specimens are placed in the center of the respective countries because no

extension at $72^{\circ} \mathrm{C}(7 \mathrm{~min})$. For ITS, the thermocycler protocol was as follows: $95^{\circ} \mathrm{C}(5 \mathrm{~min})$ followed by $35-40$ cycles of $95^{\circ} \mathrm{C}(30-60 \mathrm{~s}), 48^{\circ} \mathrm{C}$ or $51^{\circ} \mathrm{C}$ (30-60 s), $72^{\circ} \mathrm{C}(30-90 \mathrm{~s})$, and final extension at $72^{\circ} \mathrm{C}(8-10 \mathrm{~min})$. PCR products were checked on a $1 \%$ agarose gel and amplicons were purified using either ExoSAP-IT (Affymetrix, Santa Clara, CA, USA) or a Silica Bead DNA gel extraction kit (Thermo Fisher Scientific, Waltham, MA, USA), according to the manufacturers' protocols. Cycle sequencing reactions were performed in $10 \mu \mathrm{l}$ reactions, consisting of $0.5 \mu \mathrm{l}$ ABI Big Dye Terminator ver. 3.1, $0.5 \mu \mathrm{l}$ Big Dye $5 \times$ sequencing buffer, $2 \mu \mathrm{l}$ primer at $10 \mu \mathrm{M}$ concentration, $2.5 \mu \mathrm{l}$ purified PCR product, and $4.5 \mu \mathrm{ldd \textrm {H } _ { 2 }} \mathrm{O}$. Reaction mixtures were heated to $96^{\circ} \mathrm{C}$ for $1 \mathrm{~min}$ followed by 30 cycles of $96^{\circ} \mathrm{C}(10 \mathrm{~s}), 50^{\circ} \mathrm{C}(5 \mathrm{~s})$, and $60^{\circ} \mathrm{C}(4 \mathrm{~min})$. The samples were then sequenced on an ABI PRISM coordinates were available for those specimens. The inset in the upper left corner shows the Latvian specimens in habitus. The different colors for the sites represent the different clades found in the phylogenetic trees

3130 or 3730 (Applied Biosystems, Carlsbad, CA) at one of the following institutions: the Royal Ontario Museum (Toronto, Canada), LGC Genomics (Berlin, Germany), or Macrogen SPAIN (Madrid, Spain).

Phylogenetic analyses and genetic distances

The COI dataset for the newly generated sequences was augmented by several sequences downloaded from GenBank, including samples for all known species of Placobdella, several of which were derived from specimens collected at the respective type localities; the final COI dataset included 108 terminals, 22 of which are newly sequenced. The resulting COI gene tree was used to guide the choice of specimens for ITS sequencing. The ITS dataset included 48 (15 of these are newly derived) terminals representing each major clade in the COI tree. For both 


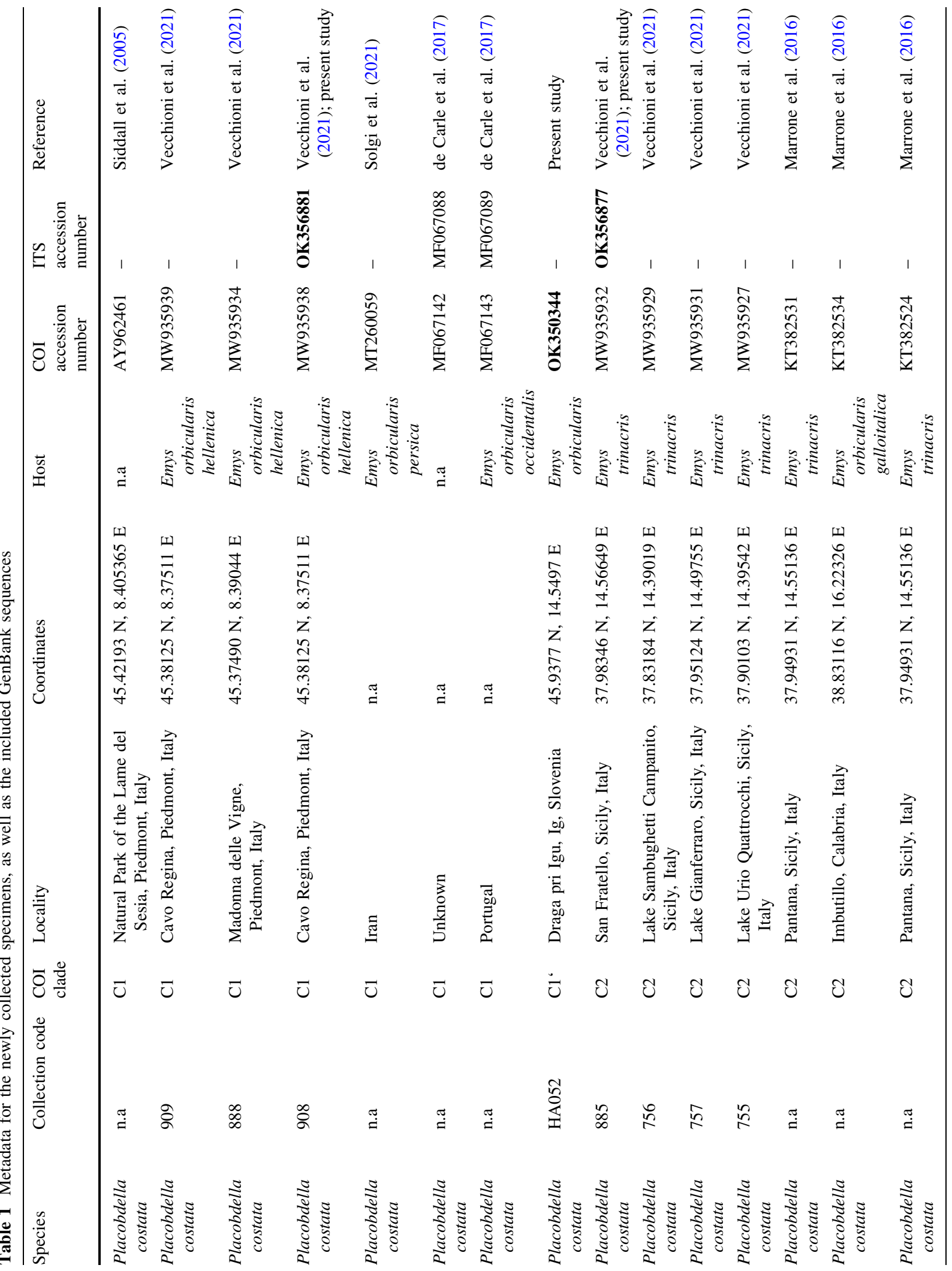




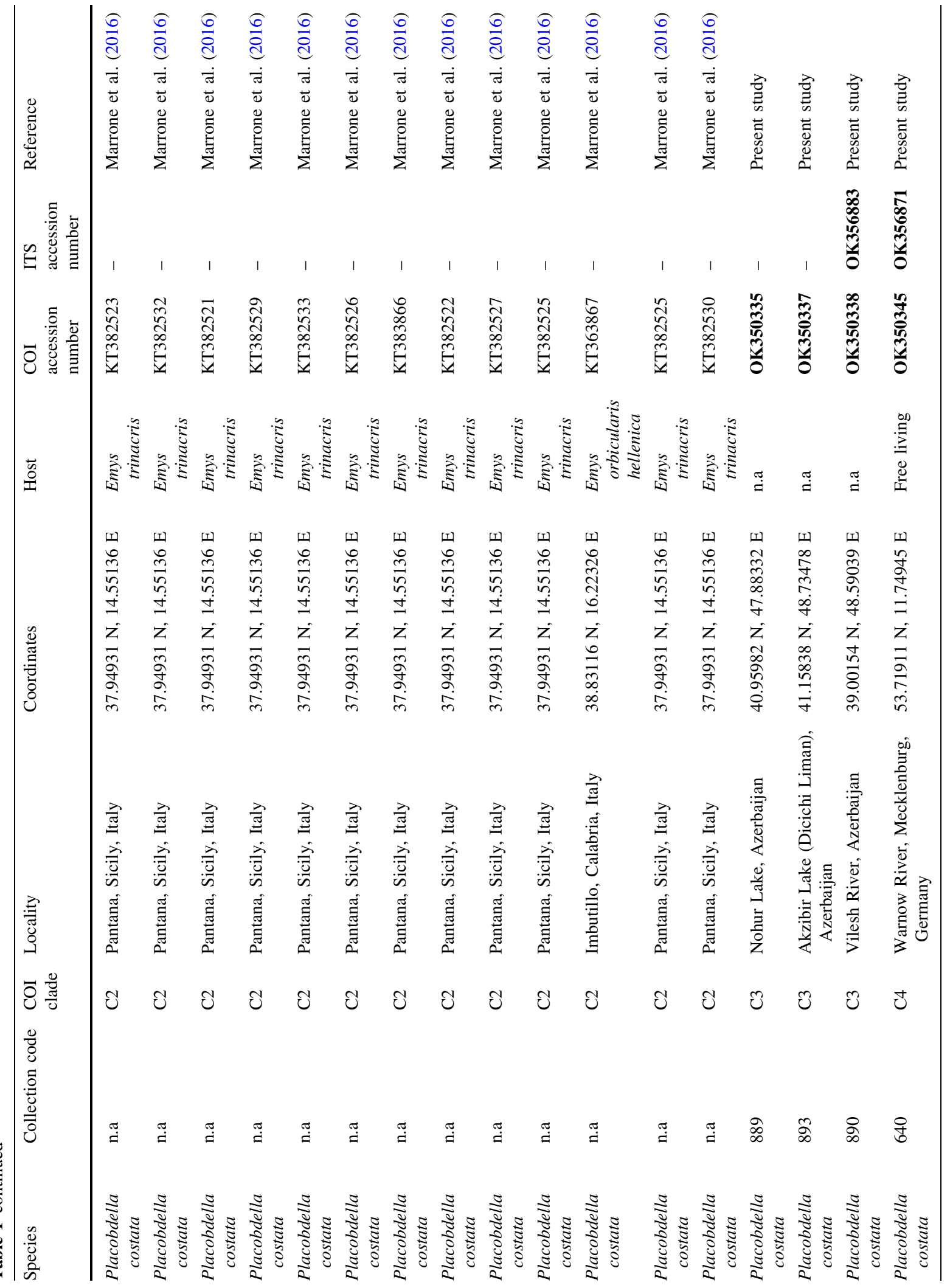




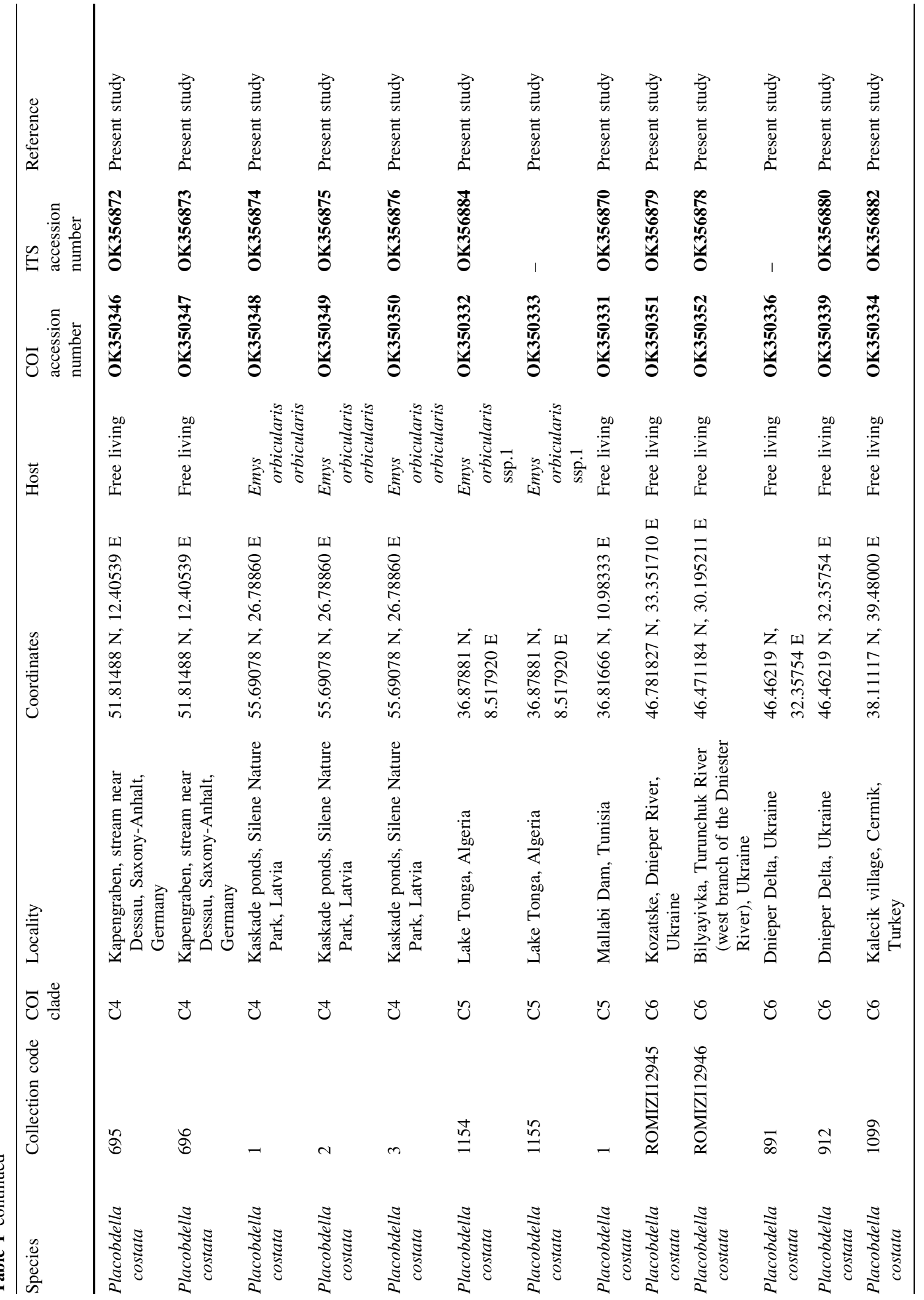




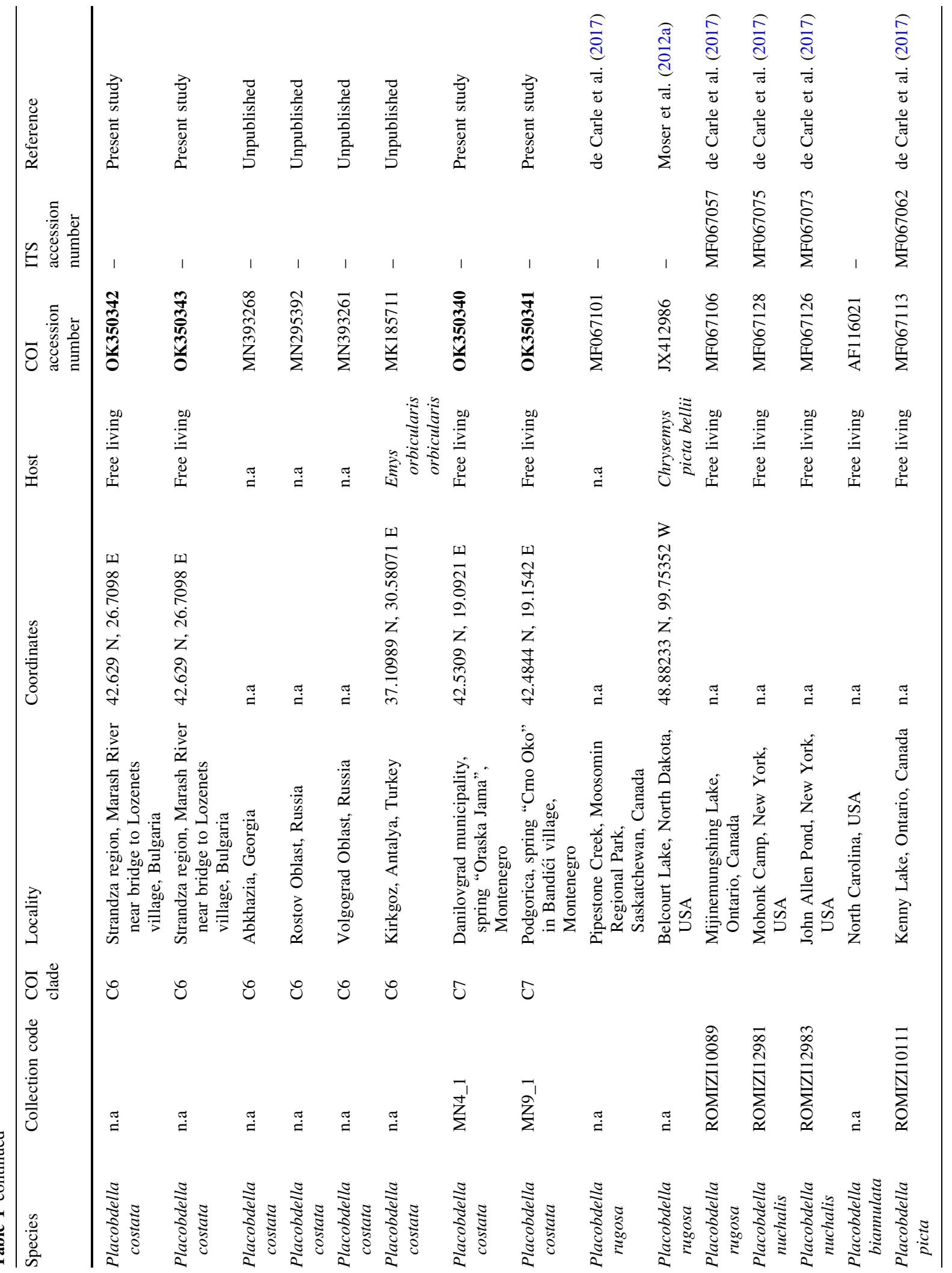




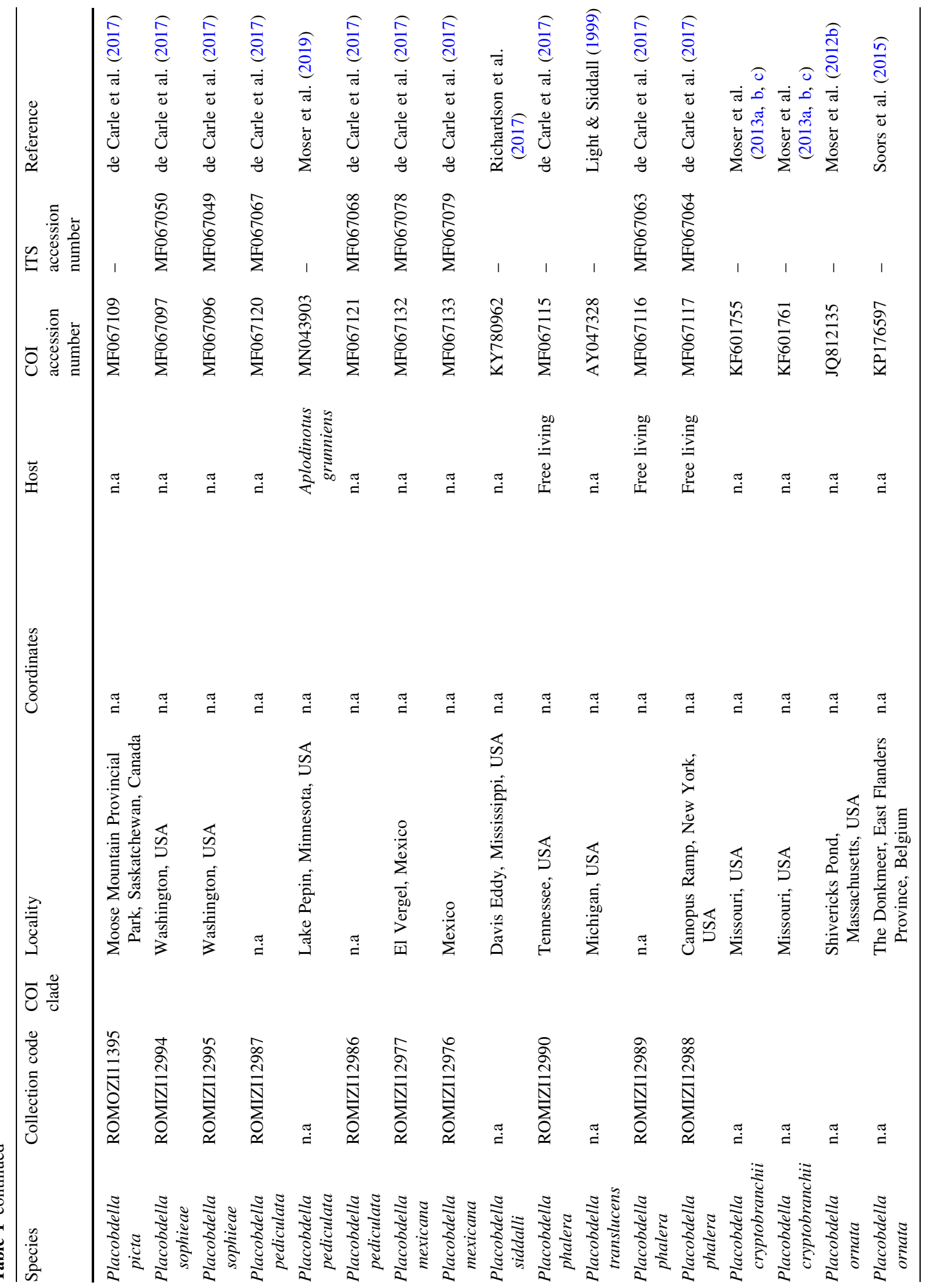




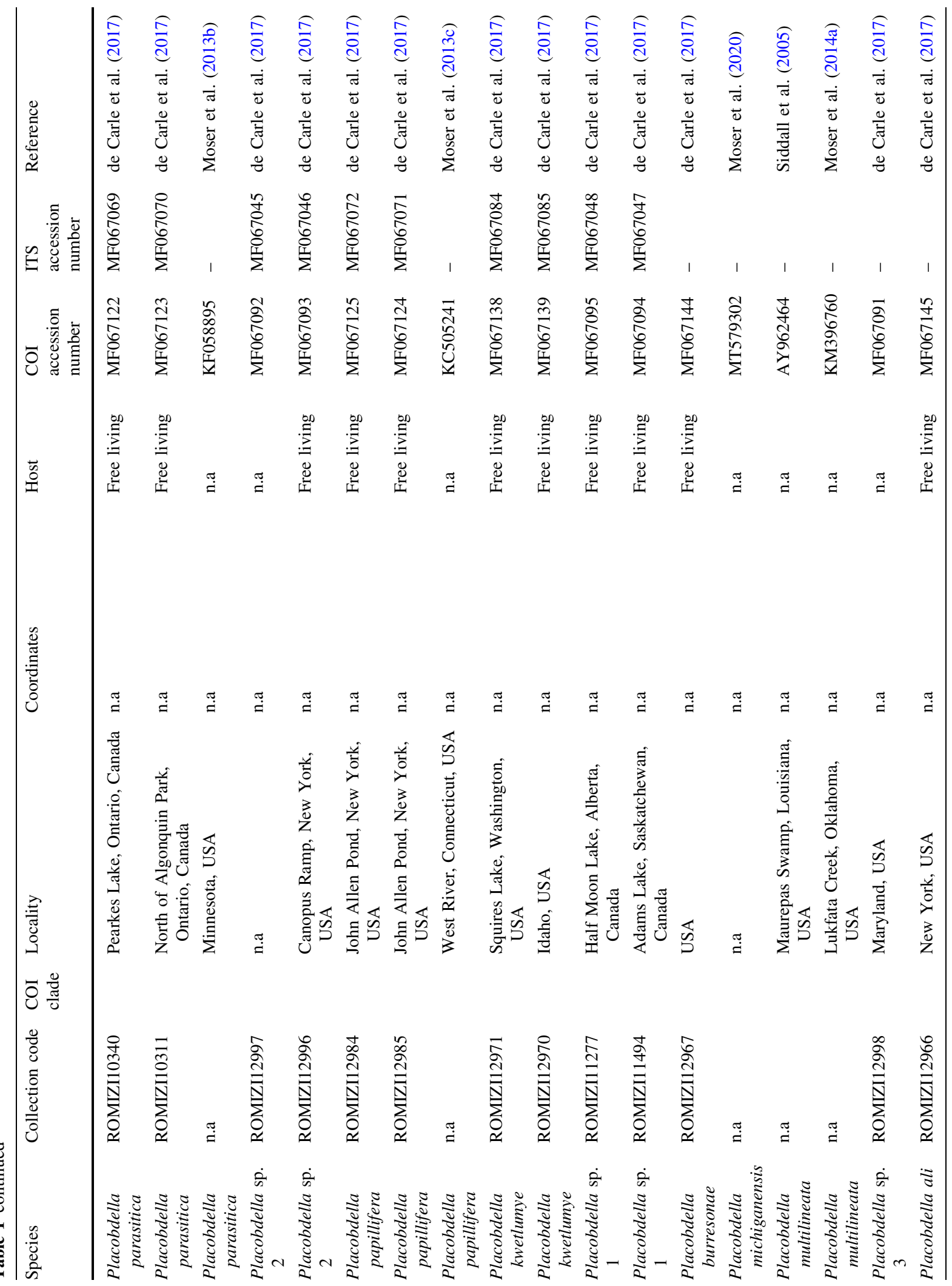




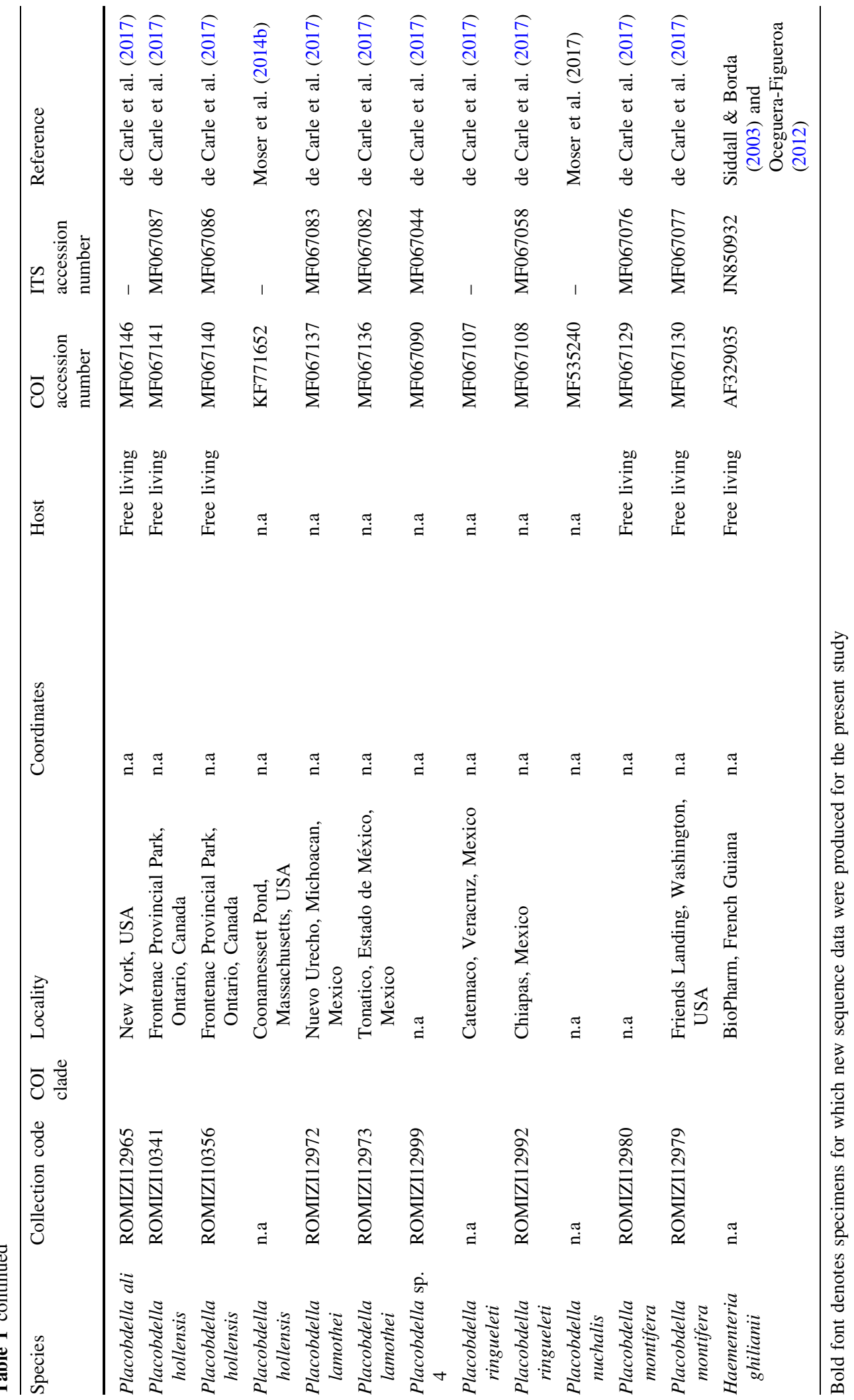


COI and ITS, sequences were aligned using the online version of MAFFT (Katoh et al., 2019) applying automatic alignment strategy with a gap opening penalty of 5.0. Mesquite ver. 3.11 (Maddison \& Maddison, 2016) and ALTER (Glez-Peña et al., 2010) were used to reformat and concatenate the datasets for phylogenetic analyses and the COI alignment was cut to cover only the "Folmer region". Phylogenetic analyses used both maximum likelihood (ML) and parsimony approaches and the trees were rooted at Haementeria ghilianii de Filippi, 1849 following the previous phylogenetic hypotheses (de Carle et al., 2017).

Prior to maximum likelihood (ML) analyses, PartitionFinder ver. 1.1.1 (Lanfear et al., 2012) was used to simultaneously estimate the optimal partitioning scheme and the best fitting model of nucleotide evolution. For this purpose, each locus was assessed separately, and so was each codon position for the protein-coding COI locus. Phylogenetic analyses were performed for each of the following datasets: (i) COI only, (ii) ITS only, and (iii) COI and ITS combined. The ML analyses were carried out using RAxML ver. 8 (Stamatakis, 2014) on the CIPRES Science Gateway platform (Miller et al., 2010). Tree searches consisted of 1000 replicates with 25 initial GAMMA rate categories and final optimization using four GAMMA shape categories; nodal support values were calculated using 1000 pseudoreplicates using the rapid bootstrap algorithm applying default settings.

In addition, parsimony analyses were performed in TNT ver. 1.5 (Goloboff \& Catalano, 2016) for each of the three datasets. New Technology searches were performed using 1000 iterations, each consisting of five rounds of ratcheting, without drifting or tree fusing and stipulating that the search be terminated if the optimal score was hit 10 times ("hits 10"). The results of the search were thereafter subjected to branch swapping using the "bbreak" command and bootstrap support was estimated through 1000 pseudoreplicates using default settings.

Following previous DNA barcoding approaches, MEGA ver. X (Kumar et al., 2018) was used to calculate genetic distances using uncorrected $p$-distances with uniform rates among sites and pairwise deletion of missing data. Standard errors were calculated via 500 bootstrap replicates with default settings.

\section{Results}

Phylogeny

All newly derived sequences are deposited in GenBank under accession numbers OK350331OK350352 (COI) and OK356870-OK356884 (ITS) (see Table 1). The final COI dataset consisted of 658 aligned sites covering the "Folmer region" and the ITS dataset consisted of 976 aligned sites; accordingly, the combined dataset consisted of 1634 aligned sites. The resulting ML trees from the analyses using the (i) COI, (ii) ITS, and (iii) combined datasets are presented in Figs. 2, 3 and 4, respectively; the corresponding parsimony trees are presented in Supplementary Figs. 1-3.

Insofar as the phylogenetic relationships of Placobdella have been discussed elsewhere (de Carle et al., 2017), the current study focuses only on $P$. costata and its closest constituents. Whereas each of the parsimony trees are largely unresolved for specieslevel relationships, the ML trees show more resolved topologies. The sister group to Placobdella costata differs between the trees and this position receives only very low support. In the COI tree, Placobdella rugosa Moore, 1901 places as the sister taxon to $P$. costata (likelihood bootstrap support $[\mathrm{LBS}]<75 \%$ ); parsimony bootstrap support [PBS] $<75 \%$ ), whereas this position is occupied by larger clades in the ITS tree [composed of $P$. rugosa, Placobdella papillifera (Verrill, 1872), Placobdella ringueleti López-Jiménez \& Oceguera-Figueroa, 2009, Placobdella sp. 4, Placobdella lamothei Oceguera-Figueroa \& Siddall, 2008, Placobdella sp. 2, Placobdella parasitica (Say, 1824), Placobdella mexicana Moore, 1898, Placobdella hollensis (Whitman, 1892), Placobdella pediculata Hemingway, 1908, Placobdella phalera (Graf, 1899), and Placobdella montifera Moore, 1906; LBS $<75 \%$; PBS $<75 \%$ ] and in the combined tree [composed of P. montifera, $P$. pediculata, Placobdella ornata (Verrill, 1872), Placobdella cryptobranchii (Johnson \& Klemm, 1977), P. phalera, Placobdella transluscens (Sawyer \& Shelley, 1976), Placobdella michiganensis (Sawyer, 1972), Placobdella burresonae Siddall \& Bowerman, 2006, Placobdella kwetlumye Oceguera-Figueroa et al., 2010, Placobdella sp. 1, Placobdella nuchalis Sawyer \& Shelley, 1976, Placobdella sophieae Oceguera-Figueroa et al., 2010, Placobdella picta (Verrill, 1872), Placobdella 
Fig. 2 Highest scoring maximum likelihood tree resulting from the analysis of the COI locus

$(\ln L=-8303.773428)$.

Likelihood bootstrap support above $75 \%$ is shown above each node and parsimony bootstrap support above $75 \%$ is shown below each node. Bold font denotes terminals for which new sequence data were produced for the present study, and GenBank accession numbers follow the taxon names. Clades C1-C7 are color-coded and are further discussed in the text

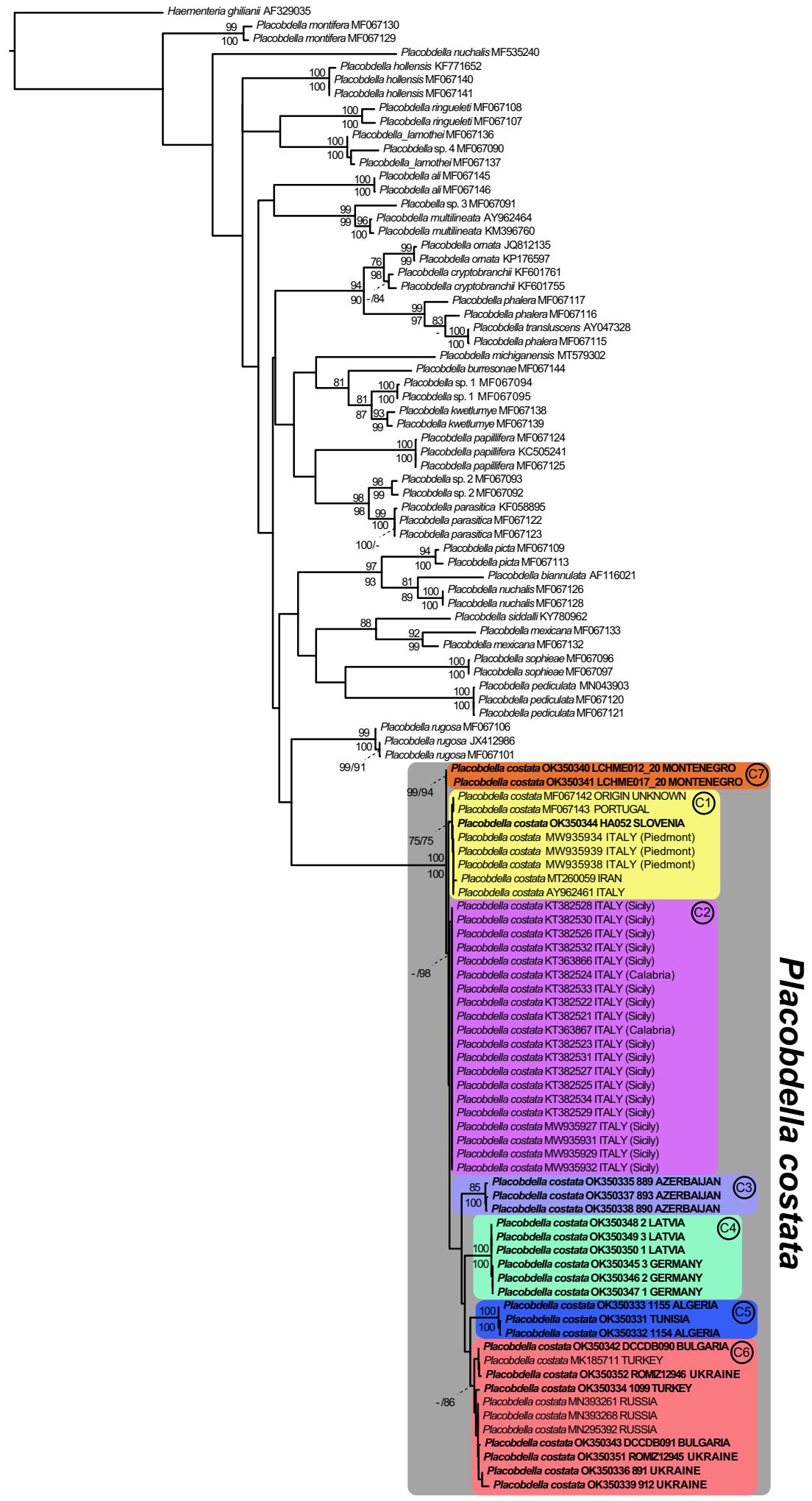

$0.5 \overline{\text { substitutions } / \text { site }}$ 


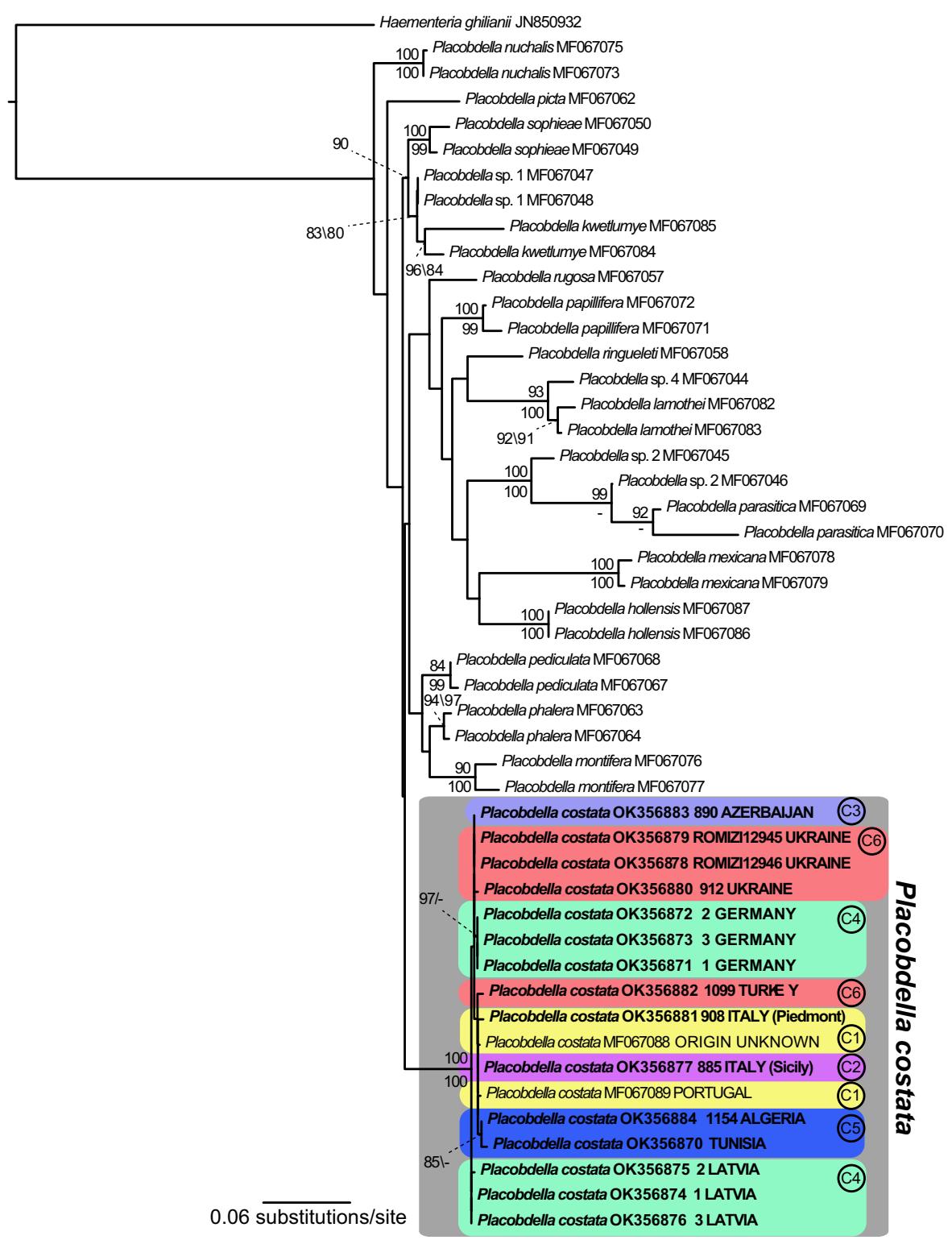

Fig. 3 Highest scoring maximum likelihood tree resulting from the analysis of the ITS locus $(\ln L=-5842.070410)$. Likelihood bootstrap support above $75 \%$ is shown above each node and parsimony bootstrap support above $75 \%$ is shown below

biannulata (Moore, 1900), and P. nuchalis; LBS < $75 \%$; PBS $<75 \%$ ]. In all trees, specimens labeled $P$. costata form a monophyletic group (LBS $=100 \%$; PBS $=100 \%$ for all trees) and both the COI and combined trees recover seven lineages within $P$. costata. The first (C1) includes specimens collected in Portugal, Iran, Slovenia, and the Piedmont region of continental Italy $(\mathrm{LBS}=75-81 \%$; PBS $=75-77 \%)$; each node. Newly sequenced specimens are denoted in bold font and GenBank accession numbers follow the taxon names. Clades C1-C6 are color-coded and are further discussed in the text

the second (C2) includes specimens collected on the Italian island of Sicily and in Calabria (southern peninsular Italy) $(\mathrm{LBS}=87 \%$; $\mathrm{PBS}=<75 \%)$; the third (C3) includes specimens collected in Azerbaijan $(\mathrm{LBS}=79-85 \% ; \quad \mathrm{PBS}=100 \%)$; the fourth (C4) includes specimens collected in Latvia and Germany (LBS $=97-100 \%$; PBS $=99-100 \%$ ); the fifth (C5) includes specimens collected in Tunisia and Algeria 
Fig. 4 Highest scoring maximum likelihood tree resulting from the analysis of the concatenated COI and ITS datasets

$(\ln L=-14,824.031552)$.

Likelihood bootstrap support above $75 \%$ is shown above each node and parsimony bootstrap support above $75 \%$ is shown below each node. Bold font denotes terminals for which new sequence data were produced for the present study. Clades $\mathrm{C} 1-\mathrm{C} 7$ are color-coded and are further discussed in the text
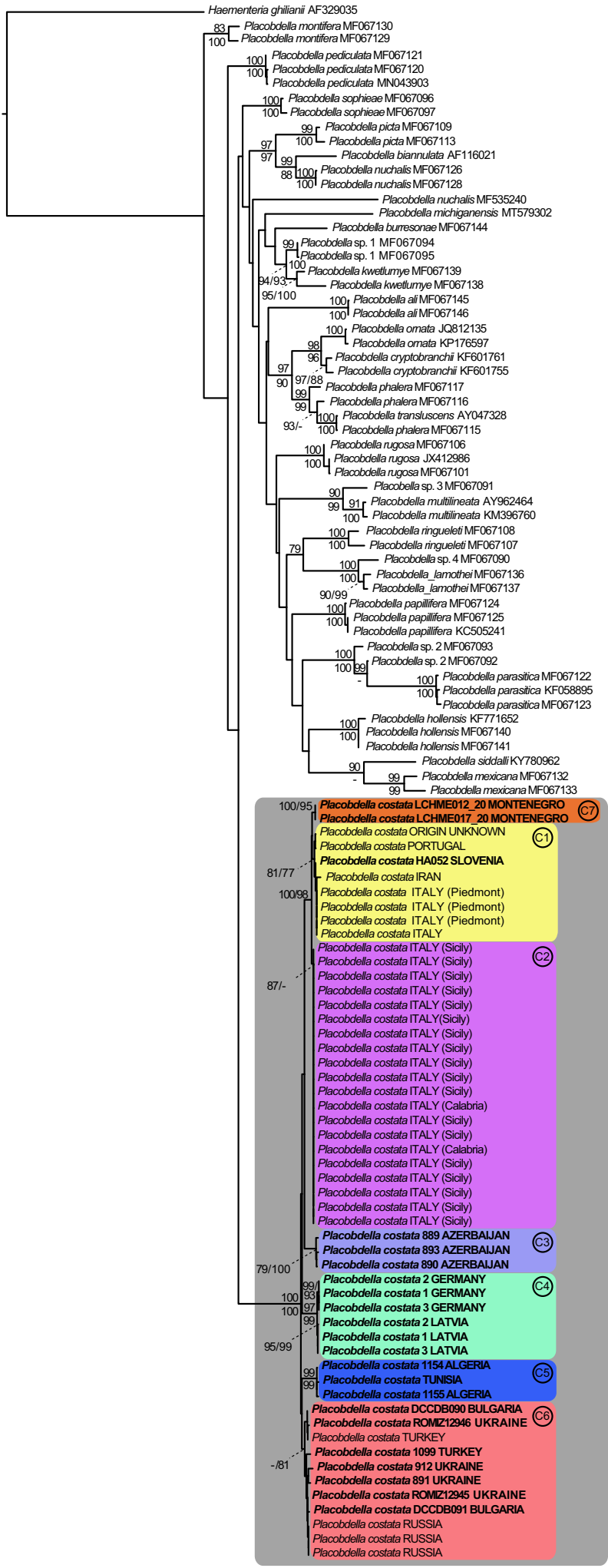
Table 2 Average COI variation between and within the different Placobdella costata lineages recovered in the COI and combined trees

\begin{tabular}{|c|c|c|c|c|c|c|c|}
\hline & $\mathrm{C} 1$ & $\mathrm{C} 2$ & $\mathrm{C} 3$ & $\mathrm{C} 4$ & $\mathrm{C} 5$ & C6 & $\mathrm{C} 7$ \\
\hline $\mathrm{C} 1$ & $0.41 \% \pm 0.15$ & 0.49 & 0.94 & 0.92 & 0.95 & 0.85 & 0.44 \\
\hline $\mathrm{C} 2$ & $1.62 \%$ & $0.00 \%$ & 0.96 & 1.02 & 0.98 & 0.83 & 0.38 \\
\hline $\mathrm{C} 3$ & $5.81 \%$ & $5.60 \%$ & $0.68 \% \pm 0.28$ & 1.03 & 1.06 & 0.94 & 0.96 \\
\hline $\mathrm{C} 4$ & $6.55 \%$ & $6.66 \%$ & $7.24 \%$ & $0.18 \% \pm 0.13$ & 0.97 & 0.85 & 0.95 \\
\hline C5 & $6.82 \%$ & $6.11 \%$ & $8.10 \%$ & $7.31 \%$ & $0.42 \% \pm 0.20$ & 0.83 & 0.94 \\
\hline C6 & $5.46 \%$ & $4.86 \%$ & $6.32 \%$ & $5.68 \%$ & $5.80 \%$ & $1.54 \% \pm 0.29$ & 0.81 \\
\hline $\mathrm{C} 7$ & $1.55 \%$ & $0.83 \%$ & $6.18 \%$ & $6.84 \%$ & $6.63 \%$ & $5.35 \%$ & $0.00 \%$ \\
\hline
\end{tabular}

The lower left triangle shows average interlineage distances with standard errors in the upper right triangle (italicized). The diagonal (bold font) shows average intralineage variation and standard errors

Table 3 Average ITS variation between and within the different Placobdella costata lineages recovered in the COI and combined trees

\begin{tabular}{lllllll}
\hline & $\mathrm{C} 1$ & $\mathrm{C} 2$ & $\mathrm{C} 3$ & $\mathrm{C} 4$ & $\mathrm{C} 5$ & $\mathrm{C} 6$ \\
\hline $\mathrm{C} 1$ & $\mathbf{0 . 5 1 \%} \pm \mathbf{0 . 2 4}$ & 0.10 & 0.22 & 0.38 & 0.18 & 0.21 \\
$\mathrm{C} 2$ & $0.22 \%$ & $\mathbf{n . a}$ & 0.17 & 0.34 & 0.21 & 0.16 \\
$\mathrm{C} 3$ & $0.51 \%$ & $0.25 \%$ & $\mathbf{n . a}$ & 0.16 & 0.25 & 0.08 \\
$\mathrm{C} 4$ & $1.02 \%$ & $0.71 \%$ & $0.27 \%$ & $\mathbf{0 . 3 5 \%} \pm \mathbf{0 . 2 2}$ & 0.37 & 0.20 \\
$\mathrm{C} 5$ & $0.54 \%$ & $0.43 \%$ & $0.68 \%$ & $0.85 \%$ & $\mathbf{0 . 3 7 \%} \pm \mathbf{0 . 2 3}$ & 0.25 \\
$\mathrm{C} 6$ & $0.56 \%$ & $0.34 \%$ & $0.19 \%$ & $0.45 \%$ & $0.78 \%$ & $\mathbf{0 . 3 7 \%} \pm \mathbf{0 . 1 5}$ \\
\hline
\end{tabular}

The lower left triangle shows average interlineage distances with standard errors in the upper right triangle (italicized). The diagonal (bold font) shows average intralineage variation and standard errors

(LBS $=99-100 \% ;$ PBS $=99-100 \%)$; the sixth (C6) includes specimens collected in Ukraine, Russia, Georgia, Bulgaria, and Turkey (LBS $<75 \%$; PBS 81-86\%); and the seventh (C7) includes specimens collected in Montenegro (LBS $=99-100 \%$; PBS = 94-95\%). We suggest that C6 represents Placobdella costata sensu stricto as it includes specimens collected in close proximity to the type locality of the species. The relationships between these clades are relatively conserved between the trees; the only difference is that $\mathrm{C} 1$ places as the sister group to $\mathrm{C} 7$ in the combined tree, whereas it places as the sister group to $\mathrm{C} 2$ in the COI tree.

The ITS tree includes fewer terminals for the $P$. costata clade and does not recover the same seven clades, although support values are largely negligible throughout the $P$. costata clade in the ITS tree (Fig. 3). Whereas the members of $\mathrm{C} 1, \mathrm{C} 4$, and $\mathrm{C} 6$ are recovered as non-monophyletic (LBS $<75 \%$; PBS $<75 \%$ ), C5
(Algeria and Tunisia) is recovered as monophyletic (LBS $=85 \%$; PBS $<75 \%$ ); note that only a single individual was included for each of $\mathrm{C} 2$ and $\mathrm{C} 3$ and no specimens were included for $\mathrm{C} 7$.

Genetic variation

Genetic distances within and between the different lineages of $P$. costata are presented in Table 2 (for COI) and Table 3 (for ITS). The average COI distances within lineages ranged between $0 \%$ (in $\mathrm{C} 2$ ) and $1.54 \% \pm 0.29$ (in C6), whereas the average COI distance between lineages ranged between $1.55 \% \pm 0.44$ (between $\mathrm{C} 1$ and $\mathrm{C} 7$ ) and $8.10 \% \pm 1.06$ (between C3 and C5). Notably, the average variation between lineages was typically an order of magnitude larger than that within lineages, suggesting the presence of an adequately sized DNA barcoding gap for each of the comparisons. These 
results lend further strength to the hypothesis that five species-level taxa are present among our " $P$. costata" sequences $(\mathrm{C} 1, \mathrm{C} 2$, and $\mathrm{C} 7$ are separated by less than $1.62 \%$ COI distance and are considered the same species by the present study); for clarity, the putative species are represented by (i) $\mathrm{C} 1+\mathrm{C} 2+\mathrm{C} 7$, (ii) $\mathrm{C} 3$, (iii) $\mathrm{C} 4$, (iv) $\mathrm{C} 5$, and (v) $\mathrm{C} 6$.

The average ITS distances between lineages were much lower than those for COI. These values ranged between $0.22 \% \pm 0.10$ (between $\mathrm{C} 1$ and $\mathrm{C} 2$ ) and $1.02 \% \pm 0.38$ (between $\mathrm{C} 1$ and $\mathrm{C} 4$ ), whereas the ITS distance within lineages ranged between $0.35 \% \pm 0.22$ (within C4) and $0.51 \% \pm 0.24$ (within C1).

\section{Discussion}

As opposed to its North American counterparts, and despite its broad geographic distribution in Europe, North Africa, and Asia, P. costata is a relatively rare species compared to other members of the genus (e.g., van Haaren et al., 2004; Spyra \& Krodkiewska, 2013). In part, its scattered distribution is likely due to heavy deforestation and the resulting decrease of woodland ponds acting as suitable habitat for the species and its hosts (Spyra \& Krodkiewska, 2013). Beyond abundance, the noticeable lack of species-level diversity in Palearctic members of Placobdella could be the result of various phenomena. Prior to the analyses performed herein, it was still unknown whether or not Palearctic populations were panmictic, which would be evident if only a single species was present across the continents; the lack of any newly described Palearctic species would certainly suggest that this is the case. Investigations into the genetic diversity of Palearctic members of Placobdella are virtually non-existent (but see Marrone et al., 2016; Vecchioni et al., 2021) and collection efforts have instead largely focused on North American diversity (e.g., Oceguera-Figueroa et al., 2010; Moser et al., 2012a, b, 2014a, b; Oceguera-Figueroa \& Léon-Règagnon, 2014; de Carle et al., 2017; Mack et al., 2019). Through largely expanded geographic sampling, our results show that the COI variation between members of "Placobdella costata" are in line with the interspecific divergences shown for other, well-differentiated annelid taxa (e.g., Trontelj et al., 1996; Kvist, 2016; de Carle et al, 2017), which indicates that at least five separate species-level taxa are present in the Palearctic. It seems reasonable to suggest that Placobdella costata sensu stricto is represented by the well-supported clade C6, seeing as specimens within that clade were collected close to the type locality in southern Ukraine. It should be noted, of course, that $\mathrm{COI}$ variation alone does not provide an adequate view of species delimitation. Ecological, morphological, and behavioral data should be leveraged to inform on species boundaries for our proposed taxa.

Notwithstanding the results from the COI variation analysis, the ITS locus does not support several of the separations between clades. It has been shown that ITS evolves at a much slower rate than COI, holds less power in sorting lineages, and that phylogenetic analyses using this locus often produce unresolved topologies (e.g., Martinsson et al., 2017; de Carle et al., 2017). Judging from the relatively large COI distances, we hypothesize that speciation is still ongoing (or is very recent) in $P$. costata $s$. $l$. and that isolation between populations will lead to increased variation in ITS given the appropriate amount of time. Although genetic distances are low in ITS, we still see a certain degree of lineage sorting within this locus. In particular, this relates to $\mathrm{C} 5$ (including specimens from Algeria and Tunisia), which is present as a distinct clade also in the ITS tree (Fig. 3). Because only a single individual sequence was included for each of C2 (including specimens from Sicily and southern Peninsular Italy) and C3 (including specimens from Azerbaijan), support for these "clades" could not be ascertained from the ITS tree.

Despite the fact that only a single species of Placobdella is currently recognized in the Palearctic, historical taxonomic accounts of European placobdellloid taxa might have bearing on the present study insofar as they have suggested species names that are open to accommodate the newly discovered diversity. Moquin-Tandon (1846) described Glossiphonia catenigera (Moquin-Tandon, 1846) (= Placobdella costata) from the surrounding areas of Toulouse, France and provided both figures and a short description of its morphology, showing a striking resemblance to that of $P$. costata. Although $G$. catenigera has since been subsumed by $P$. costata via a series of taxonomic transfers, we do not exclude the possibility that the species is present among our data and should perhaps be restored to species-level status within the genus Placobdella. The same possibility exists for 
Placobdella carinata (Diesing, 1858) (= Placobdella costata), which Autrum (1936) discussed as being present in Asia Minor, Syria, and Astrachan (Russia) and for Placobdella roszkowskii Oka, 1932) (= Placobdella costata) from Tbilsi (Georgia) (see Autrum, 1936). Although robust morphological investigations of our newly collected taxa are needed, these three cases represent scenarios in which subsumed species might be re-erected on the basis of increased taxon sampling and species delimitation studies.

Interestingly, our phylogenetic analyses support the hypothesis that Palearctic diversity of Placobdella is the result of a single dispersal event from North America to Europe, insofar as the specimens of "Placobdella costata" form a monophyletic group (Figs. 2, 3, and 4); this result corroborates previous studies (Siddall et al., 2005; Bielecki et al., 2012). The local dispersal capability of $P$. costata is likely limited, seeing as members of Placobdella are typically poor swimmers and seem to preferentially disperse attached to their host (e.g., Bielecki et al., 2012). Lukin (1976) suggested that $P$. costata is the only European leech species capable of feeding on reptilian blood, although the host diversity of the species is still not fully explored. The known hosts for the species include the European pond turtle [Emys orbicularis (Linnaeus, 1758)], the Sicilian pond turtle (Emys trinacris Fritz, Fattizzo, Guicking, Tripepi, Pennisi, Lenk, Joger \& Wink, 2005), the Spanish pond turtle [Mauremys leprosa (Schweigger, 1812)], the Balkan pond turtle [Mauremys rivulata (Valenciennes, 1833)], and the Caspian turtle [Mauremys caspica (Gmelin, 1774)] (Bielecki et al., 2012; Romero et al., 2014; Arizza et al., 2016; Bashirichelkasari \& Yadollhvandmiandoab, 2017; Fediras et al., 2017; Laghzaoui et al., 2020), and few of these species are known to disperse over great distances (but see Mantziou et al. 2004; Vecchioni et al., 2020). Sapkarev (1963) recorded $P$. costata from both frogs and aquatic birds, possibly indicating that dispersal with an avian host is possible (note that the identity of the parasitized bird was not provided in that account). This could explain the expansion of its distribution into North Africa and the Middle East, but it is possible that human-mediated dispersal can account for crossing of the strait of Gibraltar. In terms of the dispersal between North America and Europe, fossil evidence suggests that Emys orbicularis was present in Europe in the early Miocene (Fritz et al., 1998; Lenk et al., 1999) and may have brought the leeches attached to their bodies (Bielecki et al., 2012). It is still unknown, however, how the freshwater hosts made the transition from North America to Europe. The P. costata/E. orbicularis system provides a prime opportunity for the study of co-evolutionary patterns between the species. However, despite concerted efforts, contemporary studies have failed to recover signs of co-evolution or co-speciation between these taxa (Marrone et al., 2016; Vecchioni et al., 2021). It therefore seems unlikely that the species diversity and speciation patterns uncovered herein for $P$. costata are driven by speciation, isolation, or dispersal of the hosts.

The present study is the first to comprehensively address the genetic variation within Palearctic members of Placobdella and our results suggest that species-level diversity may be greater than previously thought. Given the lack of both extensive sampling and investigations into the genetic structure within the species, this is not surprising, but still provides fodder for future studies into the population dynamics of Palearctic bloodfeeding leeches and their hosts. It seems likely that more unknown biodiversity will be unveiled through approaches similar to the one used in this study.

Acknowledgements Funding for this study was generously supplied by a NSERC Discovery Grant (SK) and as part of the statutory activities of the University of Silesia in Katowice (to PŚ and $Ł G)$. We thank Ester Kink, Kristen Choffe, Nuša Hrga, and Valerija Zakšek for technical support in the lab, as well as Melita Vamberger for help in the field.

Author contributions All authors designed the research; SK, SU, FM, LV, LG, and CM analyzed the data. All authors wrote, reviewed, and approved the final version of the manuscript.

Funding Funding for this study was generously supplied by a NSERC Discovery Grant (SK) and as part of the statutory activities of the University of Silesia in Katowice (to PŚ and ŁG).

Data availability All DNA sequences used in the present study are deposited in GenBank under Accession Numbers OK350331-OK350352 (COI) and OK356870-OK356884 (ITS).

Code availability Not applicable.

\section{Declarations}

Conflict of interest The authors declare that no conflict of interest exists. 
Ethical approval Not applicable.

Consent to participate All authors consent.

Consent for publication All authors consent.

\section{References}

Arizza, V., F. Sacco, D. Russo, R. Scardino, M. Arculeo, M. Vamberger \& F. Marrone, 2016. The good, the bad and the ugly: Emys trinacris, Placobdella costata and Haemogregarina stepanowi in Sicily (Testudines, Annelida and Apicomplexa). Folia Parasitologica 63: 029.

Autrum, H., 1936. Hirudineen. In: Bronn, H. G. (ed.), Klassen und Ordnungen des Tierreichs. Leipzig, Germany.

Bashirichelkasari, N. \& R. Yadollahvandmiandoab, 2017. Placobdella costata an ectoparasite for Mauremys caspica in north of Iran. Journal of Aquaculture Research and Development 8: 9-10.

Ben Ahmed, R. B., Y. Romdhane \& S. Tekaya, 2015. Checklist and distribution of marine and freshwater leeches (Annelida, Clitellata, Hirudinea) in Tunisia with identification key. Ecologica Montenegrina 2: 3-19.

Bielecki, A., J. M. Cichocka, A. Jabłoński, I. Jeleń, E. Ropelewska, A. Biedunkiewicz, J. Terlecki, J. J. Nowakowski, J. Pakulnicka \& J. Szlachciak, 2012. Coexistence of Placobdella costata (Fr. Müller, 1846) (Hirudinida: Glossiphoniidae) and mud turtle Emys orbicularis. Biologia 67: 731-738.

Cichocka, J., A. Bielecki, I. Jabłońska-Barna, Ł. Krajewski, K. Topolska, J. Hildebrand, M. Dmitryjuk, A. Biedunkiewicz, \& A. Abramchuk, 2021. The blood sucking on human by Placobdella costata (OF Müller, 1846) (Hirudinida: Glossiphoniidae): case study with notes on body form. Ecology and Evolution 00: 1-11.

de Carle, D., A. Oceguera-Figueroa, M. Tessler, M. E. Siddall \& S. Kvist, 2017. Phylogenetic analysis of Placobdella (Hirudinea: Rhynchobdellida: Glossiphoniidae) with consideration of COI variation. Molecular Phylogenetics and Evolution 114: 234-248.

Fediras, S., R. Rouag, N. Ziane, A. Olivier, A. Béchet \& S. Benyacoub, 2017. Prevalence of Placobdella costata (Fr. Mûller, 1846) (Hirudinida: Glossiphoniidae) on the European pond turtle (Emys orbicularis) in the North-East of Algeria. Herpetology Notes 10: 3-8.

Folmer, O., M. Black, W. Hoeh, R. Lutz \& R. Vrijenhoek, 1994. DNA primers for amplification of mitochondrial cytochrome c oxidase subunit I from diverse metazoan invertebrates. Molecular Marine Biology and Biotechnology 3: 294-299.

Fritz, U., 1998. Introduction to zoogeography and subspecific differentiation in Emys orbicularis (Linnaeus, 1758), pp. 1-27. In Fritz U., U. Joger, R. Podloucky, J. Servan (eds), Proceedings of the EMYS Symposium Dresden 96, Mertensiella10, Warlich, Rheinbach.

Glez-Peña, D., D. Gómez-Blanco, M. Reboiro-Jato, F. FdezRiverola, \& D. Posada, 2010. ALTER: program-oriented format conversion of DNA and protein alignments. Nucleic Acids Research Web Server issue. ISSN: 0305-1048.

Goloboff, P. A. \& S. A. Catalano, 2016. TNT version 1.5, including a full implementation of phylogenetic morphometrics. Cladistics 32: 221-238.

Iwama, R. E., A. Oceguera-Figueroa, D. de Carle, C. Manglicmot, C. Erséus, M. S. M. Na'ta'ne, M. E. Siddall \& S. Kvist, 2019. Broad geographic sampling and DNA barcoding do not support the presence of Helobdella stagnalis (Linnaeus, 1758) (Clitellata: Glossiphoniidae) in North America. Zootaxa 4671: 1-25.

Jones, S. R. M. \& P. T. K. Woo, 1990. Redescription of the leech Desserobdella phalera (Graf, 1899) n. comb. (Rhynchobdellida: Glossiphoniidae), with notes on its biology and occurrence on fishes. Canadian Journal of Zoology 68: 1951-1955.

Katoh, K., J. Rozewicki \& K. D. Yamada, 2019. MAFFT online service: multiple sequence alignment, interactive sequence choice and visualization. Briefings in Bioinformatics 20: 1160-1166.

Kumar, S., G. Stecher, M. Li, C. Knyaz \& K. Tamura, 2018. MEGA X: molecular evolutionary genetics analysis across computing platforms. Molecular Biology and Evolution 35: $1547-1549$.

Kvist, S., 2016. Does a global DNA barcoding gap exist in Annelida? Mitochondrial DNA Part A 27: 2241-2252.

Laghzaoui, E. M. \& A. Abbad, 2020. Host-parasite association of Placobdella costata (Glossiphoniidae: Hirudinea) and Mauremys leprosa (Geoemydidae: Testudinoidea) in aquatic ecosystems of Morocco. Parasitology Research 119: 3459-3467.

Lanfear, R., B. Calcott, S. Y. Ho \& S. Guindon, 2012. PartitionFinder: combined selection of partitioning schemes and substitution models for phylogenetic analyses. Molecular Biology and Evolution 29: 1695-1701.

Lenk, P., U. Fritz, U. Joger \& M. Wink, 1999. Mitochondrial phylogeography of the European pond turtle, Emys orbicularis (Linnaeus 1758). Molecular Ecology 8: 1911-1922.

Light, J. E. \& M. E. Siddall, 1999. Phylogeny of the leech family Glossiphoniidae based on mitochondrial gene sequences and morphological data. Journal of Parasitology 85: 815-823.

Lukin E. I., 1976. Pijavki presnych i solonovatich vodojemov. Fauna USSR. Pijavki. Inst. Zool. Akad. Nauk USSR, "Nauka", 484 pp.

Mabrouki, Y., R. Ben Ahmed, A. F. Taybi \& J. Rueda, 2019. An annotated checklist of the leech (Annelida: Hirudinida) species of the Moulouya River basin, Morocco, with several new distribution records and a historical overview. African Zoology 54: 199-214.

Mack, J., D. de Carle \& S. Kvist, 2019. Prey, populations, and the pleistocene: evidence for low COI variation in a widespread North American leech. Mitochondrial DNA Part A 30: 749-763.

Maddison, W. P., \& D. R. Maddison, 2016. Mesquite: a modular system for evolutionary analysis. version 3.11 [available from: http://mesquiteproject.org].

Mann, K. H., \& E. Watson, 1954. A key to the British freshwater leeches with notes on their ecology. Freshwater Biological Association, Ambleside, UK. 
Mantziou, G., N. Poulakakis, P. Lymberakis, E. Valakos \& M. Mylonas, 2004. The inter- and intraspecific status of aegean Mauremys rivulata (Chelonia, Bataguridae) as inferred by mitochondrial DNA sequences. Herpetological Journal 14: 35-45.

Marrone, F., F. Sacco, C. Kehlmaier, V. Arizza \& M. Arculeo, 2016. Some like it cold: the glossiphoniid parasites of the Sicilian endemic pond turtle Emys trinacris (Testudines, Emydidae), an example of 'parasite inertia'? Journal of Zoological Systematics and Evolutionary Research 54: 60-66.

Martinsson, S., C. Rhodén \& C. Erséus, 2017. Barcoding gap, but no support for cryptic speciation in the earthworm Aporrectodea longa (Clitellata: Lumbricidae). Mitochondrial DNA Part A 28: 147-155.

Miller, M. A., W. Pfeiffer, \& T. Schwartz, 2010. Creating the CIPRES Science Gateway for inference of large phylogenetic trees. 2010 Gatew. Comput. Environ. Work. GCE 2010 .

Moser, W. E., J. Bowerman, P. Hovingh, C. A. Peark \& A. Oceguera-Figueroa, 2010. New host and distribution records of the leech Placobdella sophieae Oceguera-Figueroa et al., 2010 (Hirudinida: Glossiphoniidae). Comparative Parasitology 81: 199-202.

Moser, W. E., D. J. Richardson, C. I. Hammond \& E. A. LazoWasem, 2012a. Redescription of Placobdella ornata (Verrill, 1872)(Hirudinida: Glossiphoniidae). Bulletin of the Peabody Museum of Natural History 53: 325-330.

Moser, W. E., D. J. Richardson, C. I. Hammond, F. R. Govedich \& E. A. Lazo-Wasem, 2012b. Resurrection and redescription of Placobdella rugosa (Verrill, 1874) (Hirudinida: Glossiphoniidae). Bulletin of the Peabody Museum of Natural History 53: 375-381.

Moser, W. E., J. T. Briggler, D. J. Richardson, C. D. Schuette, C. I. Hammond, W. A. Hopkins \& E. A. Lazo-Wasem, 2013a. Redescription and molecular characterization of Placobdella cryptobranchii (Johnson \& Klemm, 1977) (Glossiphoniidae, Hirudinida). ZooKeys 338: 1-10.

Moser, W. E., D. J. Richardson, C. I. Hammond \& E. A. LazoWasem, 2013b. Redescription of Placobdella parasitica (Say, 1824) Moore, 1901 (Hirudinida: Glossiphoniidae). Bulletin of the Peabody Museum of Natural History 54: 255-262.

Moser, W. E., D. J. Richardson, C. I. Hammond \& E. A. LazoWasem, 2013c. Redescription of Placobdella papillifera Verrill, 1872 (Hirudinida: Glossiphoniidae). Bulletin of the Peabody Museum of Natural History 54: 125-131.

Moser, W. E., D. J. Richardson, C. I. Hammond \& E. A. LazoWasem, 2014a. Redescription and molecular characterization of Placobdella hollensis (Whitman, 1892) (Hirudinida: Glossiphoniidae). Bulletin of the Peabody Museum of Natural History 55: 49-54.

Moser, W. E., D. J. Richardson, C. T. McAllister, J. T. Briggler, C. I. Hammond \& S. E. Trauth, 2014b. New host and distribution records of the leech Placobdella multilineata Moore, 1953 (Hirudinida: Glossiphoniidae). Journal of the Arkansas Academy of Science 68: 163-166.

Moser, W. E., D. J. Richardson, N. J. Schlesser, C. I. Hammond \& E. A. Lazo-Wasem, 2019. Redescription and molecular characterization of Placobdella pediculata Hemingway,
1908 (Hirudinida: Glossiphoniidae). Bulletin of the Peabody Museum of Natural History 60: 121-127.

Moser, W. E., D. J. Richardson, C. I. Hammond \& E. A. LazoWasem, 2020. Redescription and molecular characterization of Placobdella michiganensis (Sawyer, 1972) (Hirudinida: Glossiphoniidae). Bulletin of the Peabody Museum of Natural History 61: 97-102.

Moquin-Tandon, A., 1846. Monographie de la famille des Hirudinées, Vol. 1. Paris.

Oceguera-Figueroa, A., 2012. Molecular phylogeny of the New World bloodfeeding leeches of the genus Haementeria and reconsideration of the biannulate genus Oligobdella. Molecular Phylogenetics and Evolution 62: 508-514.

Oceguera-Figueroa, A. \& V. León-Règagnon, 2014. Biodiversidad de sanguijuelas (Annelida: Euhirudinea) en México. Revista Mexicana De Biodiversidad 85: S177-S189.

Oceguera-Figueroa, A. \& B. Pacheco-Chaves, 2012. Registros de sanguijuelas de Costa Rica y clave para la identificación de las especies con redescripción de Cylicobdella costaricae. Revista Mexicana De Biodiversidad 83: 946-957.

Oceguera-Figueroa, A., S. Kvist, S. C. Watson, D. F. Sankar, R. M. Overstreet \& M. E. Siddall, 2010. Leech collections from Washington State, with the description of two new species of Placobdella (Annelida: Glossiphoniidae). American Museum Novitates 3701: 1-14.

Oosthuizen, J. H. \& R. W. Davies, 1993. A new species of Theromyzon (Rhynchobdellida: Glossiphoniidae), with a review of the genus in North America. Canadian Journal of Zoology 71: 1311-1318.

Pawłowski, L. K., 1936. Pijawki (Hirudinea). Fauna Słodkowodna Polski [Leeches (Hirudinea). Polish freshwater fauna]. Warszawa, Zeszyt 26: 1-176.

Pawłowski, L. K., 1968. Pijawki (Hirudinea). Katalog Fauny Polski. [Leeches (Hirudinea). Catalogue of Polish fauna]. XI. PWN, Warszawa 3: 1-94.

Richardson, D. J., W. E. Moser, C. I. Hammond, E. A. LazoWasem, C. T. McAllister \& E. E. Pulis, 2017. A new species of leech of the genus Placobdella (Hirudinida, Glossiphoniidae) from the American alligator (Alligator mississippiensis) in Mississippi, USA. ZooKey 667: 39-49.

Romero, D., J. Duarte, L. Narváez-Ledesma, M. Á. Farfán \& R. Real, 2014. Presence of the leech Placobdella costata in the south of the Iberian Peninsula. Acta Parasitologica 59: 259-262.

Sağlam, N., 2001. First record of the leech Placobdella costata (Hirudinoidea: Glossiphoniidae) in Turkey. Zoology in the Middle East 23: 113-118.

Sağlam, N., U. Kutschera, R. Saunders, W. M. Saidel, K. L. Balombini \& D. H. Shain, 2018. Phylogenetic and morphological resolution of the Helobdella stagnalis species-complex (Annelida: Clitellata: Hirudinea). Zootaxa 4403: 61-86.

Sapkarev, J. A., 1963. Die Fauna Hirudinea Mazedoniens. I. Systematik und Okologie der Hirudinea des Prespa-Sees. Bulletin Scientifique / Conseil Des Académies Des Sciences Et Des Arts De La RSF De Yougoslavie 8: 7-8.

Sawyer, R. T., 1986. Leech Biology and Behaviour, Clarendon Press, UK:

Scardino, R., M. Arculeo, V. Arizza, G. Bazan, M. Lo Valvo, F. Marrone, \& L. Vecchioni, 2022. New distributional data on 
Haemogregarina stepanowi (Apicomplexa) and Placobdella costata (Hirudinea) parasitising the Sicilian pond turtle Emys trinacris (Testudines). Natural History Sciences, Milano doi: 10.4081/nhs.2022.544 [Epub Ahead of Print].

Schulz, C. A., M. V. Thomas, S. Fitzgerald \& M. Faisal, 2011. Leeches (Annelida: Hirudinida) parasitizing fish of Lake St. Clair, Michigan, USA. Comparative Parasitology 78: 73-83.

Siddall, M. E. \& E. Borda, 2003. Phylogeny and revision of the leech genus Helobdella (Glossiphoniidae) based on mitochondrial gene sequences and morphological data and a special consideration of the triserialis complex. Zoologica Scripta 32: 23-33.

Siddall, M. E. \& J. Bowerman, 2006. A new species of glossiphoniid leech from Rana pretiosa (Amphibia: Ranidae) in Oregon. Journal of Parasitology 92: 855-857.

Siddall, M. E. \& S. S. Desser, 1990. Gametogenesis and sporogonic development of Haemogregarina balli (Apicomplexa: Adeleina: Haemogregarinidae) in the leech Placobdella ornata. Journal of Protozoology 37: 511-520.

Siddall, M. E. \& S. S. Desser, 1991. Merogonic development of Haemogregarina balli (Apicomplexa: Adeleina: Haemogregarinidae) in the leech Placobdella ornata (Glossiphoniidae), its transmission to a chelonian intermediate host and phylogenetic implications. Journal of Parasitology 77: 426-436.

Siddall, M. E. \& S. S. Desser, 2001. Transmission of Haemogregarina balli from painted turtles to snapping turtles through the leech Placobdella ornata. Journal of Parasitology 87: 1217-1218.

Siddall, M. E. \& E. S. Gaffney, 2004. Observations on the leech Placobdella ornata feeding from bony tissues of turtles. Journal of Parasitology 90: 1186-1188.

Siddall, M. E., R. B. Budinoff \& E. Borda, 2005. Phylogenetic evaluation of systematics and biogeography of the leech family Glossiphoniidae. Invertebrate Systematics 19: 105-112.

Sket, B. \& P. Trontelj, 2008. Global diversity of leeches (Hirudinea) in freshwater. Hydrobiologia 595: 129-137.

Solgi, R., A. Raz, S. Zakeri, A. T. Kareshk, A. Yousef, A. Jarehan \& N. D. Djadid, 2021. Morphological and molecular description of parasitic leeches (Annelida: Hirudinea) isolated from rice field of Bandar Anzali, North of Iran. Gene Reports 23: 101162.
Soors, J., J. Mertens, W. E. Moser, D. J. Richardson, C. I. Hammond \& E. A. Lazo-Wasem, 2015. Molecular confirmation of the North American leech Placobdella ornata (Verrill, 1872) (Hirudinida: Glossiphoniidae) in Europe. BioInvasions Records 4: 185-188.

Spyra, A. \& M. Krodkiewska, 2013. The significance of woodland ponds in the conservation of rare species: a case study of Placobdella costata (F. Müller) (Hirudinida: Glossiphoniidae). Polish Journal of Ecology 61: 613-619.

Stamatakis, A., 2014. RAxML version 8: a tool for phylogenetic analysis and post-analysis of large phylogenies. Bioinformatics 30: 1312-1313.

Trontelj, P., B. Sket, P. Dovč \& G. Steinbrück, 1996. Phylogenetic relationships in European erpobdellid leeches (Hirudinea: Erpobdellidae) inferred from restriction-site data of the $18 \mathrm{~S}$ ribosomal gene and ITS2 region. Journal of Zoological Systematics and Evolutionary Research 34: 85-93.

Vamberger, M. \& P. Trontelj, 2007. Placobdella costata (Fr. Müller, 1846) (Hirudinea: Glosiphoniidae), a leech species new for Slovenia. Natura Sloveniae 9: 37-42.

van Haaren, T., P. Hop, M. Soes \& D. Tempelman, 2004. The freshwater leeches (Hirudinea) of the Netherlands. Lauterbornia 52: 113-131.

Vecchioni, L., F. Marrone, M. Arculeo, U. Fritz \& M. Vamberger, 2020. Stand out from the crowd: small-scale genetic structuring in the endemic Sicilian pond turtle. Diversity 12: 343.

Vecchioni, L., F. Marrone, M. Liuzzo, D. Seglie, R. Cavalcante, G. Bazan, V. Arizza \& M. Arculeo, 2021. New molecular data attest to the absence of cospeciation patterns between Placobdella costata (Fr. Müller, 1846) (Hirudinea) and freshwater turtles (Emys spp.) in Italy. European Zoological Journal 88: 959-965.

White, T. J., T. Bruns, S. J. W. T. Lee \& J. Taylor, 1990. Amplification and direct sequencing of fungal ribosomal RNA genes for phylogenetics. PCR Protocols: a Guide to Methods and Applications 18: 315-322.

Publisher's Note Springer Nature remains neutral with regard to jurisdictional claims in published maps and institutional affiliations. 